\title{
BMJ Open Mortality and hospitalisation in the Danish Helicopter Emergency Medical Service (HEMS) population from 2014 to 2018: a national population-based study of HEMS triage
}

\author{
Karen Alstrup (D) , Jens Aage Kølsen Petersen, ${ }^{2,3}$ Stephen Sollid, ${ }^{4,5}$ \\ Søren Paaske Johnsen, ${ }^{6}$ Leif Rognås (1) ${ }^{2,3}$
}

To cite: Alstrup K, Petersen JAK, Sollid S, et al. Mortality and hospitalisation in the Danish Helicopter Emergency Medical Service (HEMS) population from 2014 to 2018: a national population-based study of HEMS triage. BMJ Open 2020;10:e038718. doi:10.1136/ bmjopen-2020-038718

- Prepublication history and additional material for this paper are available online. To view these files, please visit the journal online ().

Received 24 March 2020 Revised 21 May 2020 Accepted 09 July 2020
D Check for updates

(c) Author(s) (or their employer(s)) 2020. Re-use permitted under CC BY-NC. No commercial re-use. See rights and permissions. Published by BMJ.

For numbered affiliations see end of article.

Correspondence to

Dr Karen Alstrup; karals@rm.dk

\section{ABSTRACT}

Objective To describe characteristics and outcomes for patients where the Danish Helicopter Emergency Medical Service (HEMS) either transported the patient to hospital, treated the patient on scene but did not transport the patient or was dispatched but cancelled en route to the patient (aborted mission), and to assess the field triage by comparing these outcomes.

Design National population-based study.

Setting and participants HEMS dispatches are undertaken from the five Danish emergency dispatch medical centres according to national guidelines. The study analysed all primary missions with helicopter take off where the patient was admitted to hospital between $1^{\text {st }}$ October 2014 and $30^{\text {th }}$ April 2018.

Main outcome measures Mortality rates, admittance to an intensive care unit (ICU), need of mechanical ventilation and length of hospital stay (LOS).

Results 6931 patients were admitted to hospital; 3311 patients were air lifted, 164 patients were ground escorted by a HEMS physician, 1421 were assisted on scene by HEMS, but escorted by the ground units and 2035 missions were aborted. The mortality was highest among the airlifted and ground escorted patients, and lowest among the patients in the aborted mission group. Mortality for the airlifted patients increased from $8.2 \%(95 \% \mathrm{Cl}$; 7.3 to 9.2$)$ at day 1 to $19.5 \%(95 \% \mathrm{Cl} ; 18.2$ to 20.9$)$ after 1 year. The airlifted and ground escorted patients were frequently admitted to ICU and subsequently mechanically ventilated and they also had an increased LOS compared with the patients only assisted on scene by HEMS and the patients in the aborted mission group.

Conclusion Patients to whom HEMS are dispatched are often critically ill or injured and have a relatively high mortality. The patients airlifted or ground escorted to hospital by HEMS appear more critically ill or injured compared with the assisted patients and the patients in the aborted mission group. The on-scene triage seems appropriate.

\section{INTRODUCTION}

Helicopter Emergency Medical Service (HEMS) is a highly specialised and costly
Strengths and limitations of this study

- A national overview of the outcomes of the Danish Helicopter Emergency Medical Service (HEMS) population is provided.

- Lack of information about patients lost to follow-up affects the robustness of the analyses.

- The observational study design prevents any determination of a causal relationship between the use of HEMS and mortality.

resource that should be reserved to patients with suspected severe injuries and time-critical emergencies. This requires high precision in selecting the right missions for HEMS and in triaging patients on scene in need of air transportation to definitive care. The aim is to avoid unnecessary mortality and morbidity by undertriage and unnecessary costs related to overtriage.

Previous studies have shown that a substantial proportion of HEMS missions are cancelled before the team arrives at the patient. $^{1-3}$ Little is known, however, about patient outcomes in cases where HEMS is cancelled en route. ${ }^{4}$ In addition, some patients seen by the HEMS team are left to be handled by the ground emergency medical service (EMS) units instead of being airlifted to hospital.

In a recent study of the Danish HEMS, we found that missions where the HEMS team had patient contact represented roughly $60 \%$ of the dispatches. ${ }^{3}$ Among these, two-thirds of the patients were airlifted to hospital. The impact of this clinical decision-making and triage by the HEMS team is not well studied.

Knowledge about patient outcomes is essential when evaluating the use of HEMS and the appropriateness of HEMS cancellations. 
Previous studies on patient outcomes have been focussing on patient subgroups, ${ }^{56}$ whereas outcomes from studies covering entire HEMS populations are lacking.

The Danish HEMS is in a unique position in this context with a national service fully integrated in the pre-hospital healthcare system. Since its implementation on $1^{\text {st }}$ October 2014, the service has systematically collected activity data, and linkage of HEMS data to other national health registries allows for analyses of outcome and survival beyond the pre-hospital phase. The Danish registries are renowned for their comprehensiveness and high data quality. ${ }^{78}$

The aim of this study was to describe characteristics, the clinical course in hospital and the overall mortality in four HEMS patient groups: (1) patients airlifted by HEMS, (2) patients escorted in an ambulance by the HEMS physician, (3) patients assisted on scene, but not escorted to hospital by HEMS and (4) patients where HEMS was cancelled en route. Furthermore, we aimed to assess the field triage of patients by comparing these outcomes across the groups.

\section{METHODS}

\section{Study design and setting}

This study is a national population-based study. The results are presented in accordance with the Strengthening the Reporting of Observational Studies in Epidemiology (STROBE) guidelines reporting data on patients dispatched a HEMS aircraft between $1^{\text {st }}$ October 2014 and $30^{\text {th }}$ April 2018.

Denmark consists of five regions with a total population of 5.8 million inhabitants. ${ }^{9}$ It covers $45000 \mathrm{~km} 2$ with both urban and rural areas including a coastline of 8750 $\mathrm{km}$ and 70 smaller islands not connected by road to the mainland. Healthcare in Denmark is tax-funded, free of charge and includes HEMS. The 1-1-2 emergency calls are handled at the five regional emergency medical dispatch centres (EMDCs) staffed by specially trained emergency medical technicians, paramedics, nurses and doctors depending on regional differences. EMDC responsibilities include assessment of the level of urgency of the call and dispatch of an appropriate response guided by a national criteria-based protocol. ${ }^{10} 11$

EMS field services in Denmark is three-tiered. Ground ambulances operate on a local level and are staffed by emergency medical technicians or paramedics. They are supported by ground-based pre-hospital critical care teams consisting of a consultant anaesthesiologist and an emergency medical technician or a paramedic. HEMS operate on a national level with helicopter-based pre-hospital critical care teams comprising a consultant anaesthesiologist, a pilot and a specially trained paramedic. In the study period the Danish HEMS operated three helicopters responding from three bases 24 hours a day, 7 days a week.

The national HEMS dispatch protocol primarily focusses on patients with a possible time-critical emergency (eg, severe trauma, stroke, acute myocardial infarction, cardiac arrest), inter-hospital transfers and less time-critical missions to the smaller Danish islands. ${ }^{12}$ Each HEMS mission is registered in the national Danish HEMS database. The database contains medical and/or operational data on patients airlifted to hospital by HEMS, patients assisted on scene, but not airlifted to hospital by HEMS, missions cancelled en route before arriving on scene (aborted missions) and missions cancelled prior to take off (rejected missions). Telephone enquiries not leading to a HEMS mission are also registered. The HEMS physicians escort a small number of patients to hospital by ground ambulance. These patients are hereafter referred to as 'ground escorted patients'. Patients assisted on scene, but not airlifted to hospital by HEMS, may be pronounced dead or discharged on scene, or brought to hospital by a ground ambulance escorted by a ground-based pre-hospital critical care team if needed. The main reason for cancelling HEMS en route (aborted mission) was 'No need of HEMS support' as judged by EMS units already on scene. The definitions of the patient groups are displayed in table 1 . The HEMS database and the Danish pre-hospital setting have previously been described in detail. ${ }^{13} 14$

\section{Selection of participants Inclusion criteria}

The study included all primary missions leading to helicopter take off. Thus, airlifted, ground escorted and assisted patients as well as aborted missions were analysed. The analyses included patients brought to hospital and also patients with more than one HEMS dispatch during the study period.

Table 1 The definition of each of the patient groups

$\begin{array}{ll}\begin{array}{l}\text { Airlifted patients } \\ \text { Ground escorted patients }\end{array} & \begin{array}{l}\text { Patients who were escorted to hospital by the HEMS physician in a helicopter } \\ \text { Pssisted patients }\end{array} \\ \begin{array}{l}\text { Patients who were assisted on scene by HEMS, but left to be handled by the ground units instead } \\ \text { of being escorted to hospital by HEMS }\end{array} \\ \begin{array}{l}\text { Patients who were treated and escorted to hospital by the ground units as HEMS was cancelled en } \\ \text { route before arrival at the patient's side }\end{array} \\ \text { Rejected missions } & \begin{array}{l}\text { Patients who were treated and escorted to hospital by the ground units as HEMS was cancelled } \\ \text { prior to take off }\end{array}\end{array}$




\section{Exclusion criteria}

Patients pronounced dead or discharged on scene, interhospital transfers, rejected HEMS missions and phone enquiries were excluded from the study. In a substantial proportion of HEMS missions to smaller islands, HEMS mainly contribute a logistical benefit to the patient (eg, bringing patients with less urgent medical conditions and minor accidents to a mainland hospital), and hence, these missions were also excluded from the analyses.

The Civil Registration System (CRS) number is a 10-digit personal identification number, which uniquely identifies all Danish citizens and permanent residents (including immigrants) in Denmark. It is used for personal identification in Danish administrative and medical databases. We retrieved the CRS number from the Danish HEMS database for missions with a patient encounter (airlifted, ground escorted and assisted patients). For missions where no patient encounter occurred (aborted missions) the CRS number could not be registered in the HEMS database. In these cases, a combination of the date and time of alarm and the patient's location was used to manually look for the patient's CRS number in the different regional dispatch software. If two or more CRS numbers were registered within the same helicopter dispatch record, this mission were excluded from the study. We also excluded patients with a missing or invalid CRS number and missions with obvious registration errors.

\section{Patient and public involvement}

No patients were involved in the design of the study.

\section{Data sources and variables}

We retrieved data on mortality from the Danish Civil Registration System (DCRS) containing daily updated vital status for all Danish citizens and permanent residents in Denmark. ${ }^{15} 16$

The Danish National Patient Register (DNPR) is a population-based administrative registry with a complete nationwide coverage since 1978. It provides access to the patient's hospitalisation histories and diagnoses classified according to the Danish version of the WHO International Classification of Diseases, $10^{\text {th }}$ edition (ICD-10). ${ }^{17}$ From the DNPR we retrieved information regarding hospital destination (defined as the first receiving hospital; university hospital vs District General Hospital (DGH), admittance to an intensive care unit (ICU), treatment with a mechanical ventilator, total length of hospital stay (LOS) as well as the first specific ICD-10 diagnosis applied during the hospital stay.

Calculation of the Charlson comorbidity index (CCI) based on ICD-10 diagnoses 10 years back in time from the date of the alarm resulting in a request for HEMS attendance were also retrieved from the DNPR. This method has been described by Sundararajan et al and validated in a Danish population. ${ }^{18}$ Primary (main reason for hospital contact) and secondary (supplementary diagnoses related to the primary hospital contact) diagnostic codes as well as outpatient diagnoses were used in the calculation. The CCI was grouped into $\mathrm{CCI}=0, \mathrm{CCI}=1$ to 2, $\mathrm{CCI}=3$ to 4 and $\mathrm{CCI}=/>5$ as described by Charlson et $a l^{20}$

\section{Outcomes}

We divided the patients into four groups according to the type of mission: (1) airlifted patients, (2) ground escorted patients, (3) assisted patients and (4) aborted missions.

Outcomes included mortality rates at day 1 (defined as death on the day or the day after the dispatch of HEMS), day 30 and after 1 year, as well as hospital destination (university hospital vs DGH), secondary transfer to a university hospital within 24 hours if first receiving hospital was a DGH, proportion of patients admitted to an ICU, proportion of patients in need of mechanical ventilation and total hospital LOS. In addition, we examined the distribution of ICD-10 diagnoses among the patient population.

\section{Statistical analyses}

We used descriptive statistics for non-parametric data including numbers and proportions, and median and IQR when appropriate. Logistic regression (quantile regression) was used to analyse differences between medians. The Kaplan-Meier method was used to estimate cumulative mortality rates including 95\% CIs at day 1 and day 30, and after 1 year. Patients in the survival analysis were followed until death, emigration or 1 year after alarm, whichever came first.

Missing data (CRS number) were not substituted.

Statistical advice was provided by an expert statistician (JV) at Aalborg University. Data obtained from the Danish HEMS database, the DCRS and the DNPR were merged through the CRS number in the Research Service's secure data management platform and further processed and analysed using Stata (Stata Statistical Software V.15.1, StataCorp, College Station, Texas, USA).

\section{Ethics}

The Danish Data Protection Agency (No. 1-16-02-40-17) and the Danish National Board of Health (No. 3-30132049/1) approved the study. An approval from the research ethics committee system was not required for this observational study (No. 1-10-72-4-17).

\section{RESULTS}

\section{Characteristics of study subjects}

The inclusion of the patients is displayed in figure 1 . A total of 13391 HEMS entries were registered in the HEMS database during the study period; 13211 of these were HEMS dispatches. In 1699 cases the mission was rejected prior to take off; most often due to adverse weather conditions $(n=1467)$. Thus, 11512 missions resulted in helicopter take off. Of these, 749 were interhospital transfers, 1399 were missions to an island not connected by road to the Danish mainland and in 112 cases more than one CRS number were reported from 


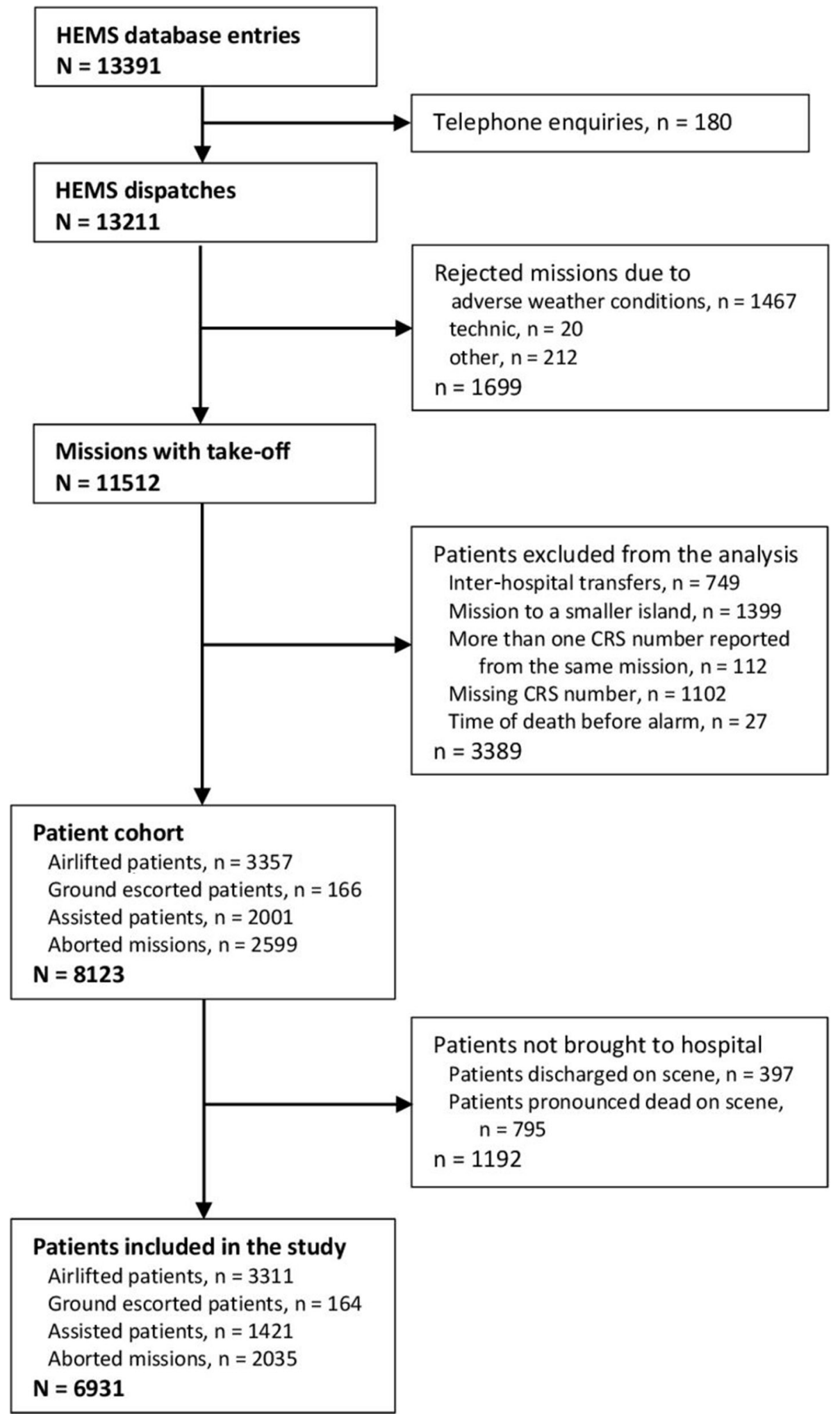

Figure 1 Study flow diagram of HEMS patients included in the study. CRS,Civil Registration System; HEMS, Helicopter Emergency Medical Service; technic, technical.

the same mission. Missing CRS number were observed in 1102 cases: 220 among the airlifted patients, 4 among the ground escorted patients, 173 among the assisted patients and 705 among the patients where HEMS was cancelled. Missions with time of death registered before the alarm (representing a registration error) represented 27 cases.
As a result, data from 8123 patients were analysed. Out of these, 1192 patients were either pronounced dead $(n=795)$ or discharged on scene $(n=397)$. In total, 6931 patients were brought to hospital and included in the study; 3311 patients were airlifted by HEMS to hospital, 164 patients were ground escorted to hospital by a HEMS 
Table 2 Demographics and comorbidity for airlifted patients, ground escorted patients, assisted patients and patients in the aborted mission group brought to hospital $(n=6931)$

\begin{tabular}{|c|c|c|c|c|c|}
\hline & $\begin{array}{l}\text { Airlifted } \\
\text { patients } \\
n=3311\end{array}$ & $\begin{array}{l}\text { Ground } \\
\text { escorted } \\
\text { patients } n=164\end{array}$ & $\begin{array}{l}\text { Assisted } \\
\text { patients } \\
n=1421\end{array}$ & $\begin{array}{l}\text { Aborted } \\
\text { missions } \\
n=2035\end{array}$ & Total $\mathrm{n}=6931$ \\
\hline \multicolumn{6}{|l|}{ Demographics } \\
\hline Age, median (IQR) & $60(46$ to 71$)$ & 56 (30 to 71$)$ & 55 (29 to 70$)$ & 57 (33 to 71$)$ & 57 (39 to 71$)$ \\
\hline \multicolumn{6}{|l|}{ Gender } \\
\hline Male, n (\%) & $2334(70.5)$ & $109(66.5)$ & $870(61.2)$ & $1228(60.3)$ & 4541 (65.4) \\
\hline \multicolumn{6}{|l|}{ Comorbidity } \\
\hline \multicolumn{6}{|l|}{$\mathrm{CCl}$ groups } \\
\hline $0, \mathrm{n}(\%)$ & $2156(65.1)$ & $88(53.7)$ & $941(66.2)$ & $1280(62.9)$ & $4465(62.6)$ \\
\hline 1 to $2, \mathrm{n}(\%)$ & $756(22.8)$ & $42(25.6)$ & $306(21.5)$ & $479(23.5)$ & $1583(23.5)$ \\
\hline Acute myocardial infarction (1), $\mathrm{n}(\%)$ & $204(6.2)$ & $10(6.1)$ & $67(4.7)$ & $138(6.8)$ & $419(6.0)$ \\
\hline Congestive heart failure (1), n (\%) & $168(5.1)$ & $16(9.8)$ & $69(4.9)$ & $105(5.2)$ & $358(5.2)$ \\
\hline Peripheral vascular disease (1), n (\%) & $196(5.9)$ & $8(4.9)$ & $91(6.4)$ & $126(6.2)$ & $421(6.1)$ \\
\hline Cerebral vascular disease (1), n (\%) & $264(8.0)$ & $26(15.9)$ & $141(9.9)$ & $217(10.7)$ & $648(9.3)$ \\
\hline Chronic pulmonary disease (1), $n(\%)$ & $228(6.9)$ & 30 (18.3) & $120(8.4)$ & $216(10.6)$ & $594(8.6)$ \\
\hline Diabetes (2), n (\%) & $319(9.6)$ & $28(17.1)$ & $135(9.5)$ & $212(10.4)$ & $694(10.0)$ \\
\hline Renal disease (2), n (\%) & $107(3.2)$ & $8(4.9)$ & $41(2.9)$ & 65 (3.2) & $221(3.2)$ \\
\hline Any cancer (2), n (\%) & $130(3.9)$ & $13(7.9)$ & $106(7.5)$ & $153(7.5)$ & $402(5.8)$ \\
\hline
\end{tabular}

$\mathrm{CCl}$; Charlson comorbidity index.

*Weight in the $\mathrm{CCl}$ for selected diagnoses.

physician in an ambulance, 1421 were assisted on scene, but not brought to hospital by HEMS, 2035 patients were handled solely by the ground units as the HEMS mission were aborted.

Table 2 displays the distribution of age and gender as well as comorbidity in each of the patient groups. The overall median age was 58 (39 to 72), and roughly twothirds of the patient population were men.

The proportion of patients with no comorbidity $(\mathrm{CCI}=0)$ was $62.6 \%$. Six per cent of the study population had severe comorbidity represented by a CCI of 5 or more. The CCI profile in each of the patient groups was fairly similar although ground escorted patients had a slightly higher proportion of patients with CCI of 3 to 4 and CCI of 5 or more. In addition to the cardiological and vascular diseases it appears that diabetes, chronic pulmonary disease and cancer contribute the most to the burden of chronic disease among the HEMS patient population.

In the online supplementary file 1 , baseline characteristics for the entire population $(n=8123)$ are displayed. The distribution of patients according to each specific diagnosis in the CCI including the weight for each diagnosis are summarised in the online supplementary file 2.

\section{Mortality}

Cumulative mortality rates for the four patient groups are presented in table 3 and visualised in the Kaplan-Meier curve (figure 2). The highest mortality at day 1 , day 30 and after 1 year were observed among the ground escorted patients (14.6\% (95\% CI; 10.1 to 21.0 ), $26.8 \%$ (95\% CI; 20.7 to 34.3 ) and $33.0 \%$ (95\% CI; 26.4 to 40.7$)$ ) followed by the airlifted patients (8.2\% (95\% CI; 7.3 to 9.2$), 16.2 \%$ (95\% CI; 15.0 to 17.5$)$ and $19.5 \%$ (95\% CI; 18.2 to 20.9$)$ ). Patients in the aborted mission group had the lowest mortality rates $(3.4 \%$ (95\% CI; 2.7 to 4.3$), 6.0 \%$ (95\% CI; 5.1 to 7.2 ) and $10.3 \%$ (95\% CI; 9.0 to 11.7$)$ ). There was no difference in the day 1 mortality $(8.2 \%$ (95\% CI; 7.3 to 9.2) and $7.5 \%$ (95\% CI; 6.2 to 9.0$)$ ) among the airlifted and the assisted patients.

Cumulative mortality rates for the entire study population $(n=8123)$ are presented in the online supplementary file 3 .

Hospital destination, length of hospital stay, ICU admittance and mechanical ventilation

The majority $(84.7 \%)$ of the airlifted patients and around half of the ground escorted patients were brought to a university hospital (table 4). For assisted patients and 
Table 3 Unadjusted cumulative mortality rates according to the type of mission for patients brought to hospital $(n=6931)$

\begin{tabular}{|c|c|c|c|c|}
\hline & $\begin{array}{l}\text { Airlifted patients } \\
\mathrm{n}=3311\end{array}$ & $\begin{array}{l}\text { Ground escorted } \\
\text { patients } n=164\end{array}$ & $\begin{array}{l}\text { Assisted patients } \\
n=1421\end{array}$ & $\begin{array}{l}\text { Aborted missions } \\
\mathrm{n}=2035\end{array}$ \\
\hline \multicolumn{5}{|l|}{ Mortality } \\
\hline $\begin{array}{l}\text { Cumulative mortality rate } \\
(95 \% \mathrm{Cl}) \text {, day } 1\end{array}$ & $8.2 \%$ (7.3 to 9.2$)$ & $14.6 \%$ (10.1 to 21.0$)$ & $7.5 \%(6.2$ to 9.0$)$ & $3.4 \%$ (2.7 to 4.3$)$ \\
\hline $\begin{array}{l}\text { Cumulative mortality rate } \\
(95 \% \mathrm{Cl}) \text {, day } 30\end{array}$ & $16.2 \%(15.0$ to 17.5$)$ & $26.8 \%$ (20.7 to 34.3 ) & $10.3 \%$ (8.8 to 12.0$)$ & $6.0 \%$ (5.1 to 7.2$)$ \\
\hline $\begin{array}{l}\text { Cumulative mortality rate } \\
(95 \% \mathrm{Cl}) \text {, day } 365\end{array}$ & $19.5 \%$ (18.2 to 20.9 ) & $33.0 \%$ (26.4 to 40.7$)$ & $14.9 \%$ (13.2 to 16.9$)$ & $10.3 \%(9.0$ to 11.7$)$ \\
\hline
\end{tabular}

patients in the aborted mission group, $12.1 \%$ and $11.2 \%$, respectively, were brought to a university hospital. All four groups had a low incidence $(0.3 \%$ to $3 \%)$ of secondary transfers to a university hospital within 24 hours after first being admitted to a DGH.

The proportion of airlifted and ground escorted patients who were admitted to an ICU were $30.5 \%$ and $40 \%$, respectively, and roughly $85 \%$ in both these groups of ICU patients needed mechanical ventilation. For the assisted patients and patients in the aborted mission group, about $7 \%$ were admitted to an ICU and about half of these ICU patients were mechanically ventilated. The median LOS was increased for airlifted and ground escorted patients (4 (1 to 11 ) and 3 (0 to 11 ) days, respectively), compared with 0 for both the assisted patients $(0$ to 3 ) and patients in the aborted mission group (0 to 2). Figure 3 illustrates the distribution of LOS in the four patient groups. The widest range was observed among the airlifted patients (0 to 494 days).

\section{Diagnoses}

Table 4 also summarises the diagnostic profiles for the different patient groups according to ICD-10. The two ICD-10 chapters most frequently used to describe the Danish HEMS patients were chapter IX "Diseases of the circulatory system" (36\%) and chapter XIX "Injury, poisoning and certain other consequences of external

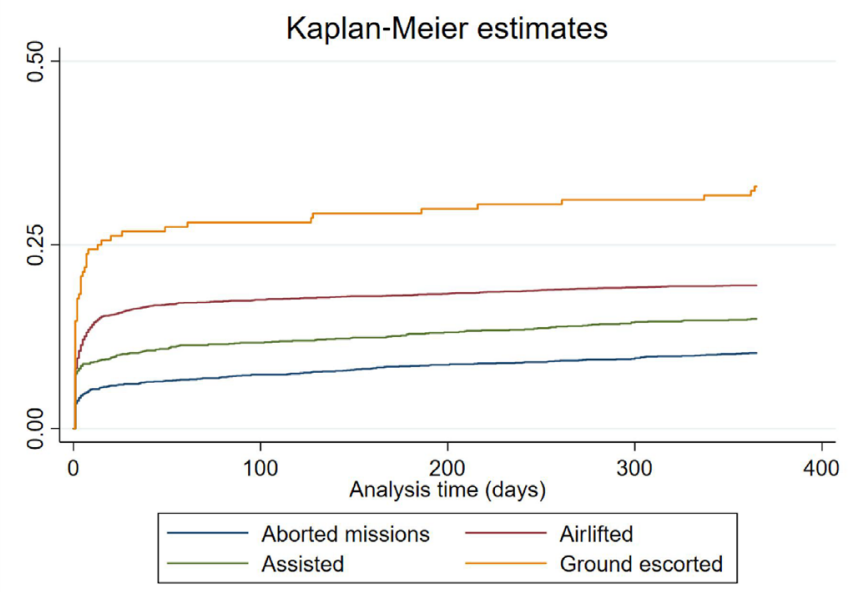

Figure 2 Kaplan-Meier cumulative mortality curves grouped according to the type of mission. causes" (28\%). Eight per cent of the patients kept their non-specific observational diagnosis (ICD-10 chapter XXI "Factors influencing health status and contact with health services") throughout their entire hospital stay.

It appears that the proportion of patients diagnosed with a disease of the circulatory system was higher among the airlifted and the ground escorted patients (56\% and $31 \%$, respectively) compared with the assisted patients $(15 \%)$ and the patients in the aborted mission group $(17 \%)$, while the proportions of patients diagnosed within "Injury, poisoning and certain other consequences of external causes" were almost the same in each of the patient groups. The complete diagnostic profile including first diagnosis assigned and first specific diagnosis assigned are presented in online supplementary files 4 and 5 .

\section{DISCUSSION}

\section{Principal findings}

In this national cohort study 8123 cases were analysed and 6931 patients included. The ground escorted patients had the highest mortality followed by the airlifted patients. They were frequently admitted to the ICU and often needed mechanical ventilation. These patients also had an increased LOS compared with the patients assisted on scene by HEMS and patients in the aborted mission group. We found no difference in the day 1 cumulative mortality between the airlifted and assisted patients. The proportion of patients with no comorbidity $(\mathrm{CCI}=0)$ was $62.6 \%$.

Almost two-thirds of the patient population had no previous registered comorbidities, and nearly two-thirds were categorised into two main diagnostic groups: "Diseases of the circulatory system" comprising both cardiovascular and neurovascular diagnoses, and "Injury, poisoning and certain other consequences of external causes" comprising the trauma patients.

\section{Strengths and weaknesses of the study}

A major strength of this study is its high data quality, the comprehensiveness of the registries used and the fact that it provides a national and nearly complete picture of the outcomes of the Danish HEMS population. Furthermore, the Danish healthcare system is tax-funded and free at 
Table 4 Hospitalisation and main diagnostic groups according to the type of mission ( $n=6931)$

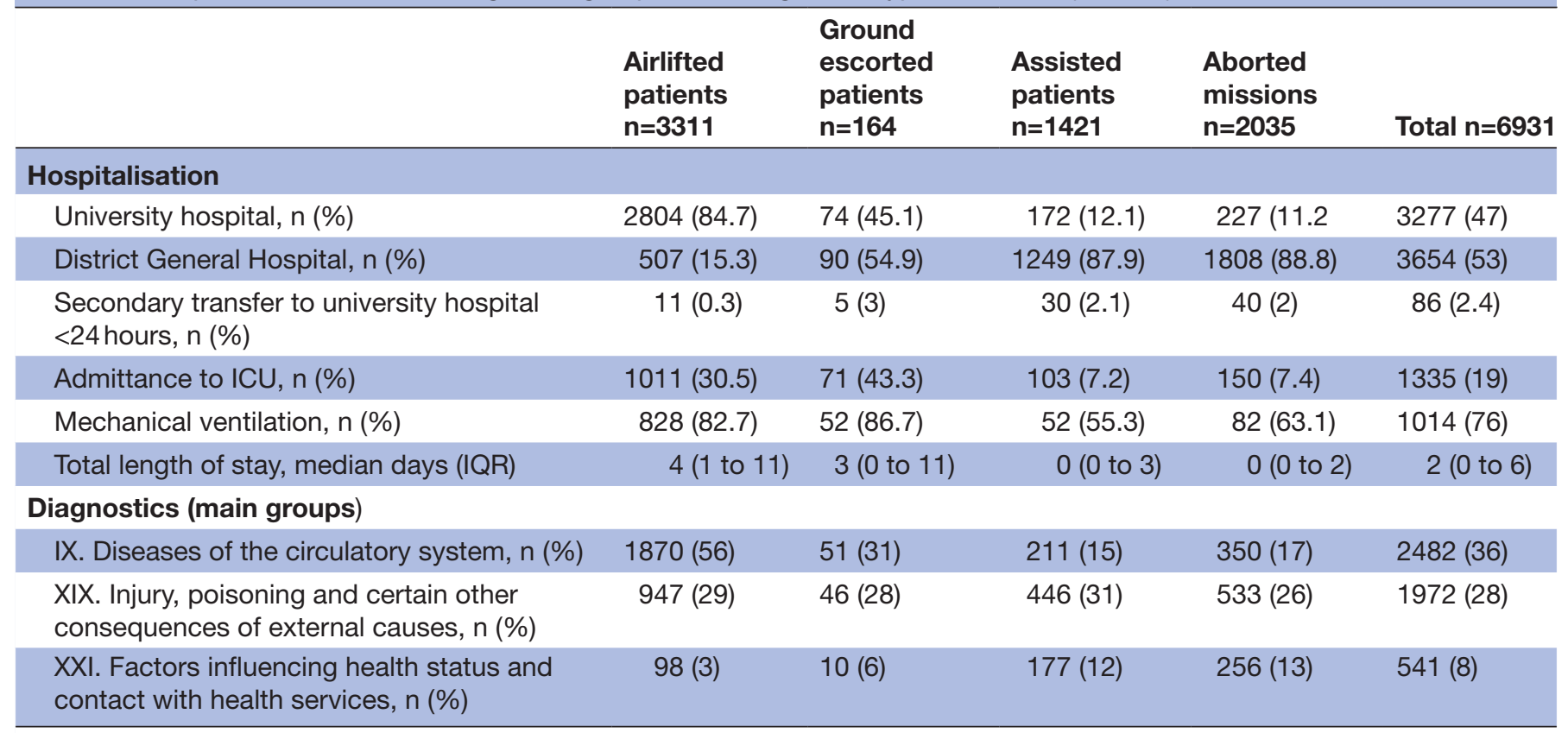

ICU, intensive care unit.

the point of access and thus, a genuine population-based study was ensured.

However, lack of validation of some diagnoses in the DNPR can potentially introduce bias and affect the interpretation of the results. The unknown number of patients with chronic diseases handled by the general practitioners alone together with incomplete registrations of some diagnoses in the DNPR, may affect the calculation of the CCI and leave unmeasured confounding.

Also, we did not have the opportunity to assess possible preventable deaths although such an evaluation could add valuable knowledge about the on-scene treatment, decision-making and triage.

Furthermore, the dispatching software is not designed for research purposes leading to a number of missing

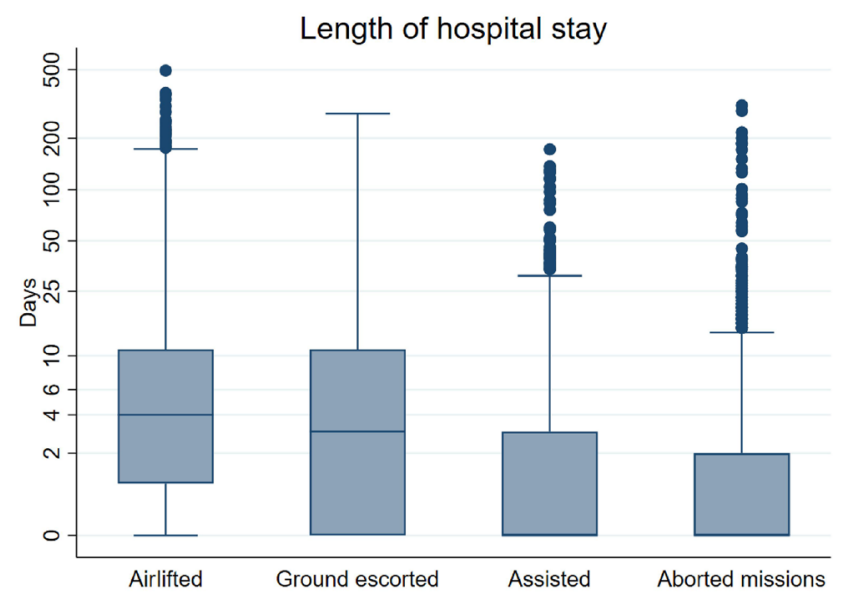

Figure 3 Box plot of length of hospital stay for the four patient groups (logarithmic scale).
CRS numbers, which especially applies for the patients in the aborted mission group. Lack of information about those patients affects the robustness of the analyses.

Study limitations also include the observational study design preventing any determination of a causal relationship between the use of HEMS and mortality.

The generalisability of this study may be substantial for other highly specialised physician-paramedic-staffed pre-hospital critical care teams operating in comparable settings with an overall similar case-mix.

\section{Other studies}

Pre-hospital studies rarely report data on a national level, and variations in study design and population, as well as organisational and geographical setting, limit a direct comparison of our results with those in previous studies. Two Danish studies have described mortality and diagnostics among pre-hospital patients; one regional study investigated unselected patients transferred to hospital by ground ambulances $^{21}$ and one single centre study reported data from a Danish ground-based physician-staffed pre-hospital critical care service. ${ }^{22}$ The mortality at day 1 and day 30 in these studies were $1.8 \%$ and $4.7 \%$, respectively, among the ambulance patient population, while for the patients admitted to hospital by the critical care team, the mortality at day 30 was $5.7 \%$. In both studies non-specific diagnostic codes were most frequently used. This was followed by "Injury, poisoning and certain other consequences of external causes" (chapter XIX) among the ambulance population, and by "Diseases of the circulatory system" (chapter IX) among the population attended to by the ground-based physician-staffed pre-hospital critical care team. In the latter study, the diagnostic profile was described according 
to the initial symptoms presented on scene, which was in contrast to the use of in-hospital assigned ICD-10 diagnoses reported in our study. The mortality rates in both studies were considerably lower than that reported in this study, suggesting that the Danish EMDCs with the current HEMS dispatch criteria are capable of primary targeting HEMS to severely ill and injured patients. Also, the diagnostic pattern and case-mix seems different in our study compared with those in the two other Danish non-HEMS studies. ${ }^{21} 22$

In a recently published study from Japan reporting characteristics for critically ill or injured patients, the mortality in patients brought to tertiary emergency centres by physician-staffed EMS was $22 \%$ compared with $14 \%$ in-patients treated by non-physician-EMS. ${ }^{23}$ This study did not distinguish physician-staffed helicopter EMS from physician-staffed ground EMS. They also reported diagnostic pattern according to the WHO ICD-10, and found that the two main diagnostic groups used were "Diseases of the circulatory system" (45\%) and "Injury, poisoning and certain other consequences of external causes" $(34 \%)$. Although not identical, these results are in line with our findings regarding trends in diagnostic distribution and mortality among pre-hospital patients.

Patient outcomes after HEMS cancellations in one Norwegian region has recently been described by $\emptyset_{\text {sterås }}$ et $a l^{4}$ The study compared mortality and hospitalisation history among patients who were airlifted to hospital by HEMS with patients who were transported in a ground ambulance due to (HEMS) concurrencies. The study demonstrated a similar in-hospital mortality in the HEMS group and the ambulance group, but there was a higher incidence of ICU admittance and an increased LOS among the HEMS patients compared with the ambulance patient group. The authors concluded that the HEMS team were able to prioritise between concurrent missions selecting the most critically ill patients for HEMS. When only analysing data from patients with a life-threatening condition, there was an increased survival in the HEMS group indicating that HEMS may have an impact on patient outcomes in this patient population.

In our study almost two-thirds of the patients had no (recognised) previous diseases $(\mathrm{CCI}=0)$. This finding was in line with results from the above-mentioned Japanese and Danish studies; both these studies reported a CCI of 0 in more than half of the patients. ${ }^{22} 23$

\section{Interpretation}

Danish HEMS patients appeared to be severely ill or injured with a short-term mortality for the airlifted and ground escorted patients ranging from $8.2 \%$ to $26.8 \%$. The risk of dying within 1 year after having been airlifted or ground escorted to hospital by HEMS was $19.5 \%$ and $33 \%$, respectively.

The airlifted and the ground escorted patients also had a higher incidence of admittance to the ICU, were more often mechanically ventilated and had an increased LOS compared with the assisted patients and the patients in the aborted mission group. Few secondary transfers to a university hospital within 24 hours after the HEMS dispatch were observed suggesting that the HEMS teams are able to perform an appropriate triage and prioritisation on scene selecting the patients who need treatment at a university hospital and those who need to be escorted (by air or by road). This is supported by a recent study where we demonstrated that patients escorted by HEMS had an increased severity score and more often had a critical care intervention performed compared with the assisted patients. ${ }^{3}$

Although the mortality at day 30 and day 365 among the assisted patients were lower compared with the airlifted patients, it was a surprise that the mortality at day 1 did not differ significantly between the two groups. The reason for this is unknown and needs to be further explored, but it should be noted that not all emergency conditions require air transportation to a university hospital even though they may be critically unwell, and hence, the patients might be correctly triaged to a DGH. This may for instance be the case for patients with a severe acute exacerbation in chronic obstructive pulmonary disease.

The decision whether to cancel HEMS en route is most often made by the staff at the first arriving ground unit once they have assessed the patient. The low mortality at day 1 among the patients in the aborted mission group may indicate that most of these decisions and assessments were appropriate. Nevertheless, the mortality increased to $10 \%$ at day 365 , and due to the many missing CRS numbers in this group, and our resulting inability to follow these patients, these percentages may be imprecise. Moreover, some of these patients had LOS of up to 300 days (figure 3). Factors associated with HEMS cancellation have been sparsely investigated but may be important when distinguishing between HEMS overtriage and undertriage in the dispatch of HEMS and in on-scene patient triage.

An increased burden of chronic diseases for an individual can be used as a predictor of mortality. ${ }^{20}$ Surprisingly, nearly two-thirds of the patient population in the study had no previously registered diseases suggesting that the event that caused HEMS to be dispatched was a sudden medical emergency or accident in an apparently healthy patient. However, as the CCI is based on hospital contacts only, patients with chronic diseases cared for solely by the general practitioners are not included, and therefore, the observed comorbidity of the HEMS patient population may be underestimated.

The diagnostic pattern in this study demonstrating that $64 \%$ of the patients were diagnosed with either a disease of the circulatory system or trauma, may also indicate that in most cases HEMS is dispatched to patients with possible time-critical conditions in accordance with the Danish dispatch protocol. ${ }^{12}$ However, a substantial proportion of these patients did not need to be escorted to hospital by the HEMS physician (neither by helicopter nor by ground ambulance). In particular, this seems to be the case for trauma patients (table 4). Whether this is due to an overtriage of HEMS to less urgent conditions and 
minor injuries or an inadequate patient triage on scene needs to be further explored.

Results from a Swiss study on diagnostic accuracy comparing diagnoses assigned by the pre-hospital critical care physician and in-hospital assigned diagnoses, demonstrated that correct recognition of certain conditions and injuries (eg, head, thoracic and pelvic trauma) can be a challenge in the pre-hospital setting. ${ }^{24}$ This may potentially affect transport mode, level of care (hospital destination) and outcomes.

\section{Perspectives and future research}

To our knowledge this study is the first to evaluate mortality, comorbidity, LOS and the need for ICUtreatment in a complete national HEMS patient population grouped according to different HEMS exposures (type of missions), thus providing an insight into the current dispatch of HEMS and on-scene patient triage. Because HEMS undertriage may potentially affect patient morbidity and mortality and HEMS overtriage may affect both availability and costs, an in-depth knowledge on predictors associated with the different HEMS exposures is essential.

An evaluation of the cause of death among the HEMS patients and their previous use of medication could provide more in-depth knowledge about the medical status of the patients prior to the event that caused HEMS to be dispatched.

Further, a validation study on the agreement between the pre-hospital and in-hospital assigned diagnoses is important when evaluating on-scene patient triage as decisions regarding hospital destination (level of care), on-scene treatment and mode of transport (air vs ground) are likely affected by the presumed diagnosis.

Lastly, this study was not designed to assess the impact of HEMS on patient outcomes due to a high degree of selection bias (confounding by indication). An evaluation of the benefit of HEMS on patient outcome demands a thorough risk adjustment including case matching between the groups.

\section{CONCLUSION}

Patients to whom the Danish HEMS are dispatched are often critically ill or injured and have a relatively high mortality. Patients airlifted or ground escorted to hospital by HEMS appear more critically ill or injured compared with the assisted patients and the patients in the aborted mission group. Two-thirds of the HEMS patient population were diagnosed with cardiovascular diseases, neurovascular diseases or trauma. Our results indicate that the Danish HEMS attends to the sickest patients, and that on-scene triage is appropriate.

\section{Author affiliations}

${ }^{1}$ Department of Research and Development, Pre-hospital Emergency Medical Service, Aarhus N, Denmark

${ }^{2}$ Department of Anaesthesiology, Aarhus University Hospital, Aarhus N, Denmark

${ }^{3}$ The Danish Air Ambulance, Aarhus, Denmark
${ }^{4} R \& D$, Norwegian Air Ambulance Foundation, Drobak, Norway

${ }^{5}$ Department of Quality and Health Technology, University of Stavanger, Stavanger, Norway

${ }^{6}$ Danish Center for Clinical Health Services Research, Department of Clinical Medicine, University of Aalborg, Aalborg, Denmark

Acknowledgements Lise Viskum Hansen (LVH) for assistance with data management. Jan Valentin (JV) for statistical advice.

Contributors KA, JKP, SS, SPJ and LR conceived and designed the study. KA managed the data supported by JKP and LR. JKP, SS, SPJ and LR supervised the conduct of the study. KA drafted the manuscript, and all authors contributed substantially to its revision. All authors read and approved the final manuscript.

Funding KA have received funding from the Danish HEMS research foundation and from the Health research foundation of the Central Denmark Region.

Disclaimer The foundations had no influence on the design or the conduct of this study; acquisition, analysis or interpretation of the data; preparations or approval of the manuscript; or the final decision to submit the manuscript for publication.

Competing interests KA have received funding from the Danish HEMS research foundation.

Patient and public involvement Patients and/or the public were not involved in the design, or conduct, or reporting, or dissemination plans of this research.

Patient consent for publication Not required.

Provenance and peer review Not commissioned; externally peer reviewed.

Data availability statement No data are available. The HEMS data set is located on a secure server at the 'Danish Health Authority'. According to Danish law it is not possible to move data from this server.

Open access This is an open access article distributed in accordance with the Creative Commons Attribution Non Commercial (CC BY-NC 4.0) license, which permits others to distribute, remix, adapt, build upon this work non-commercially, and license their derivative works on different terms, provided the original work is properly cited, appropriate credit is given, any changes made indicated, and the use is non-commercial. See: http://creativecommons.org/licenses/by-nc/4.0/.

ORCID iDs

Karen Alstrup http://orcid.org/0000-0002-8151-987X

Leif Rognås http://orcid.org/0000-0002-2542-565X

\section{REFERENCES}

1 Giannakopoulos GF, Lubbers WD, Christiaans HMT, et al. Cancellations of (helicopter-transported) mobile medical team dispatches in the Netherlands. Langenbecks Arch Surg 2010;395:737-45.

2 Østerås Ø, Brattebø G, Heltne J-K. Helicopter-based emergency medical services for a sparsely populated region: a study of 42,500 dispatches. Acta Anaesthesiol Scand 2016;60:659-67.

3 Alstrup K, Møller TP, Knudsen L, et al. Characteristics of patients treated by the Danish helicopter emergency medical service from 2014-2018: a nationwide population-based study. Scand J Trauma Resusc Emerg Med 2019;27:102.

4 Østerås Ø, Heltne J-K, Tønsager K, et al. Outcomes after cancelled helicopter emergency medical service missions due to concurrencies: a retrospective cohort study. Acta Anaesthesiol Scand 2018;62:116-24.

5 Galvagno SM, Haut ER, Zafar SN, et al. Association between helicopter vs ground emergency medical services and survival for adults with major trauma. JAMA 2012;307:1602-10.

6 Andruszkow $\mathrm{H}$, Schweigkofler $\mathrm{U}$, Lefering $\mathrm{R}$, et al. Impact of helicopter emergency medical service in traumatized patients: which patient benefits most? PLoS One 2016;11:e0146897.

7 Schmidt M, Schmidt SAJ, Sandegaard JL, et al. The Danish national patient registry: a review of content, data quality, and research potential. Clin Epidemiol 2015;7:449-90.

8 Lynge E, Sandegaard JL, Rebolj M. The Danish national patient register. Scand J Public Health 2011;39:30-3.

9 , 2019. Available: www.dst.dk

10 Andersen MS, Johnsen SP, Sørensen JN, et al. Implementing a nationwide criteria-based emergency medical dispatch system: a register-based follow-up study. Scand J Trauma Resusc Emerg Med 2013;21:53. 
11 Dansk index for Akuthjælp, 2014. Available: http://www.rm. $\mathrm{dk} /$ sundhed/sundhedstilbud-og-forebyggelse/prahospital/omprahospitalet/dansk-indeks/

12 Organisation TDH. Available: www.akutlaegehelikopter.dk

13 Alstrup K, Petersen JAK, Barfod C, et al. The Danish helicopter emergency medical service database: high quality data with great potential. Scand J Trauma Resusc Emerg Med 2019;27:38.

14 Lindskou TA, Mikkelsen S, Christensen EF, et al. The Danish prehospital emergency healthcare system and research possibilities. Scand J Trauma Resusc Emerg Med 2019;27:100.

15 Pedersen CB. The Danish civil registration system. Scand J Public Health 2011;39:22-5.

16 Pedersen CB, Gøtzsche H, Møller JO, et al. The Danish civil registration system. A cohort of eight million persons. Dan Med Bull 2006;53:441-9.

17 WHO. Icd-10, 10th revision. Available: http://apps.who.int/ classifications/icd10/browse/2016/en

18 Sundararajan V, Henderson T, Perry C, et al. New ICD-10 version of the Charlson comorbidity index predicted in-hospital mortality. J Clin Epidemiol 2004;57:1288-94.

19 Thygesen SK, Christiansen CF, Christensen S, et al. The predictive value of ICD-10 diagnostic coding used to assess Charlson comorbidity index conditions in the population-based Danish national Registry of patients. BMC Med Res Methodol 2011;11:83.

20 Charlson ME, Pompei P, Ales KL, et al. A new method of classifying prognostic comorbidity in longitudinal studies: development and validation. J Chronic Dis 1987;40:373-83.

21 Christensen EF, Larsen TM, Jensen FB, et al. Diagnosis and mortality in prehospital emergency patients transported to hospital: a population-based and registry-based cohort study. BMJ Open 2016;6:e011558.

22 Mikkelsen S, Lossius HM, Toft P, et al. Characteristics and prognoses of patients treated by an anaesthesiologist-manned prehospital emergency care unit. A retrospective cohort study. BMJ Open 2017;7:e014383.

23 Ohbe $\mathrm{H}$, Isogai S, Nakajima M, et al. Physician-manned prehospital emergency care in tertiary emergency centers in Japan. Acute Med Surg 2019;6:165-72.

24 Hasler RM, Kehl C, Exadaktylos AK, et al. Accuracy of prehospital diagnosis and triage of a Swiss helicopter emergency medical service. J Trauma Acute Care Surg 2012;73:709-15. 